\title{
Preparation of Palladium Catalyst from Bauxite Ore and Using for Kerosene Treatment
}

\author{
Wafa Muhammad Ali Muhammad Saeed ${ }^{* 1}$, Qaidar Salim Jarjis ${ }^{2}$ \\ ${ }^{1,2}$ Department of Chemistry, College of Education for Pure Science, University of Mosul, Mosul, Iraq \\ E-mail: ${ }^{1 *}$ wafam4181@gmail.com, ${ }^{2}$ qaidarsalim406@uomosul.edu.iq
}

(Received August 09, 2020; Accepted September 20, 2020; Available online March 01, 2021)

DOI: 10.33899/edusj.2020.127951.1103, (c) 2020, College of Education for Pure Science, University of Mosul.

This is an open access article under the CC BY 4.0 license (http://creativecommons.org/licenses/by/4.0/).

\begin{abstract}
The research was aimed to used bauxite ore that has a high aluminum minerals which available in AlHussainiyat near al-Anbar district as a source of alumina which it used as a catalyst support after being loaded with palladium metal, The components of both bauxite ore and prepared catalyst were studied by X-ray diffraction and fluorescence as well as thermogravimetric analysis (TGA) of the prepared catalyst, After this the catalyst was used in the treatment of kerosene which is distilled at $\left(150-260 \mathrm{C}^{0}\right)$ under different conditions of the (temperature, reaction time and the ratio of catalyst) to know the optimal reaction conditions that determid by measuring the (FTIR) and chemical analysis. The optimal conditions: temperature was $\left(250 \mathrm{C}^{0}\right)$, reaction time was (2hours) and the catalyst ratio was $(2 \%)$. The catalyst appeard the ability to dehydrogenation reaction and reforming to form olefinic and aromatic compounds. The research also included the study of n-paraffins separated from kerosene samples that were treating in different temperatures $\left(150,200,250 \mathrm{C}^{0}\right)$ using $\left({ }^{1} \mathrm{HNMR}\right)$. The results showed the ability of the catalyst towards catalytic cracking and converting n-paraffins to iso-paraffins
\end{abstract}

Keywords: Kerosene, palladium, catalysts, alpha alumina)

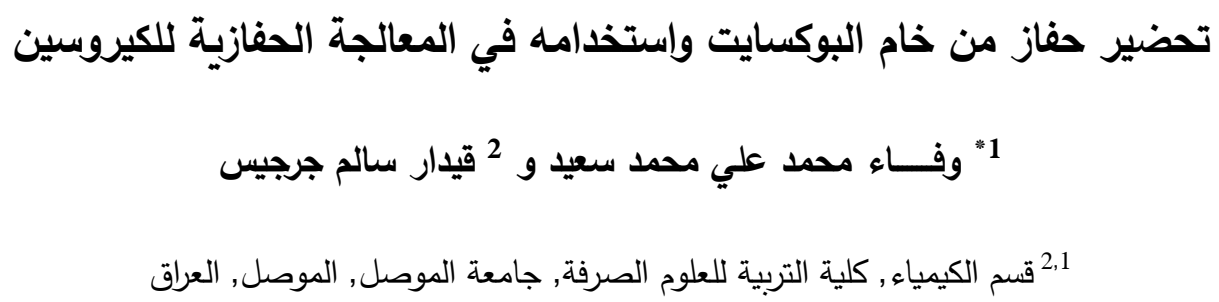

ملخص البحث :

يهـف البحث إلى إســتخدام خام البوكسـايت الغني بعنصــر الالمنيوم المتوفر في منطقة الحســينيات في محافظة الانبار

كمصدر للالومينا المتعادلة وإستخدامها كمادة ساندة للحفاز , إذ تم تحليل خام البوكسايت بإستخدام تقنيتي حيود وفلورة الاثعة السينية

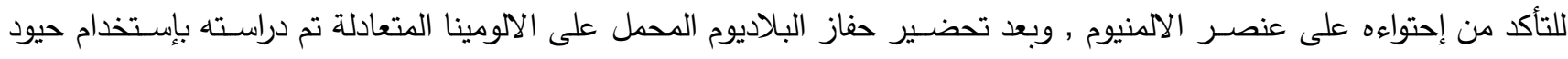
وفلورة الاثعة السينية فضلا عن التحليل الحراري الوزني (TGA ), ثم درست قدرته التهن التحفيزية من خلال تطبيقه في معالجة الكيروسين(

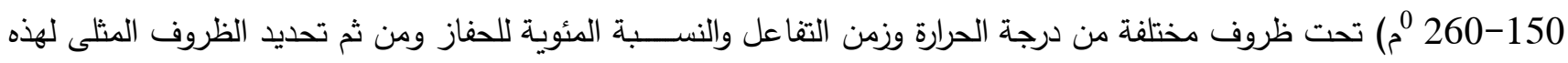
المعالجة وكانت افضـل درجة حرارة (250 0) وزمن تفاعل (2سـاعة) ونسـبة حفاز (2) (20), ودرســ النماذج المعالجة للكيروسـين

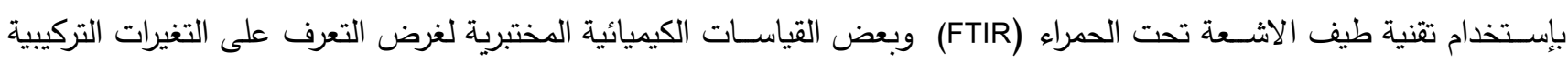

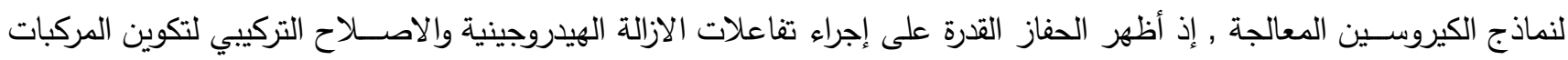


الاوليفينية والاروماتية , كما تضـــن البحث إجراء دراســة للبارافينات المسـتقيمة المفصــولة من الكيروسـين غير المعالج والنماذج

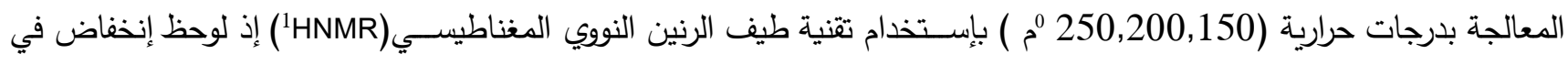

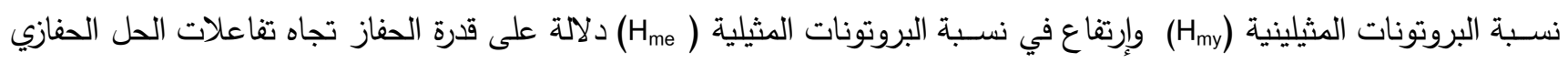
وتحول قسم من البارافينات إلى أيزومراتها المتفرعة.

الكلمات الدالة: الكيروسين , البلاديوم , الحفازات , الفا ألومينا

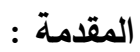

تمتلك الخامات الطينية خصـائص مميزة تتمثل بالتركيب العالي المســامية والمســاحة الســـية العالية لذلك تســخدم في الصـناعات النفطية لغرض ازالة الاصـماغ او المواد المكونه لها من الكازولين وفي تتقية زيوت التثـحيم بالاضــافة الى اسـتخدامها

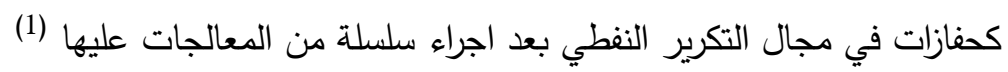
ويعد البوكسايت من الخامات الطينية المهمة لكونه يتكون من مزيج من المعادن تثكل اكاسيد الالمنيوم نسبة عالية منها فضلا عن عن

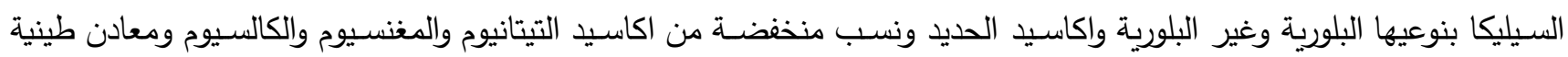
(2). اخرى مثل الكاؤلينات

توجد رواسب البوكسايت عادة في المناطق الاستوائية او شبه الاستوائية حيث تتكون نتيجة لعمليات التعرية الجوية لصخور سيليكات الالمنيوم التي تكون بهيئة صـخور (متحولة ، نارية او رسـوبية) ويستخدم في مجالات واسـعة مثل انتاج كبريتات الالمنيوم

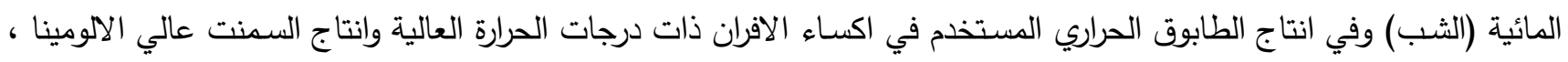
وللبوكسايت تطبيقات مهمة في الصناعة النفطية حيث يستخدم لانتاج المواد المحفزة من نوع سليكات الالمنيوم المستخدمة في مجال

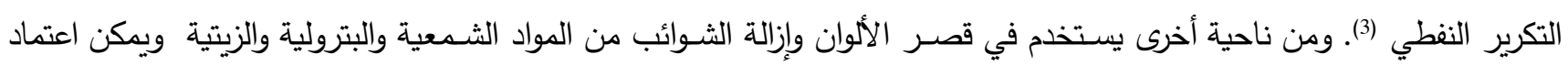

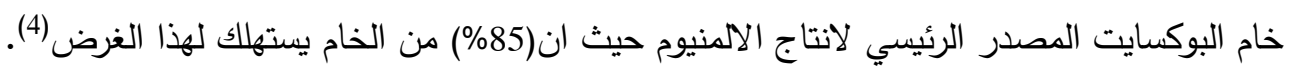

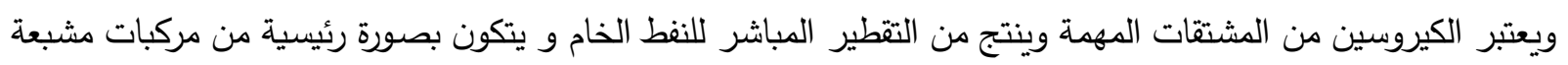

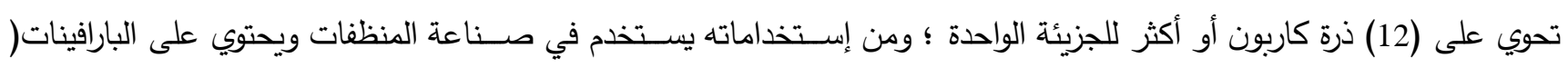
(C و $_{16}-C_{12}$ ثنائية الحلقة والمركبتانات الحلقية فضلا عن الاحماض النفثينية و الاحماض الإليفاتية (5). تمكن( ذنون ) من اجراء عملية الحل الحفازي للكيروسين بإستخدام حفاز طيني بعد إجراء سلسلة من المعالجات الفيزيائية والكيميائية على المادة الطينية, وقد أظهر الحفاز كفاءة عالية تجاه عمليات الازمرة للبارافينات المســـقتيمة وزيادة المحتوى الاروماتي والنفتيني للكيروسين (6) وقام (صـالح ) بدراســة أمكانية زيادة العدد الاوكتاني للنفثا العراقية من خلال إمرارها في الحالة الغازية على حفاز البلاتين المحمول

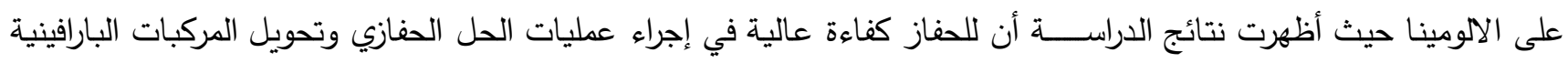

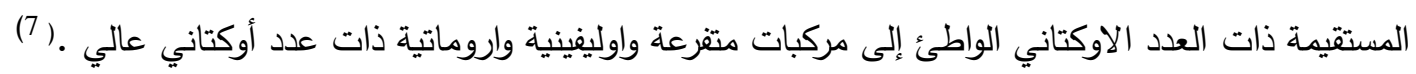

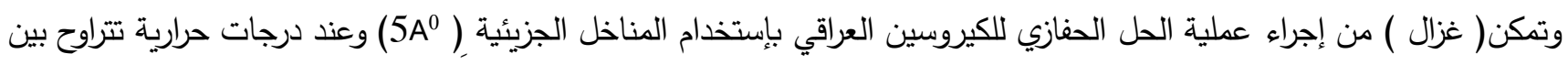

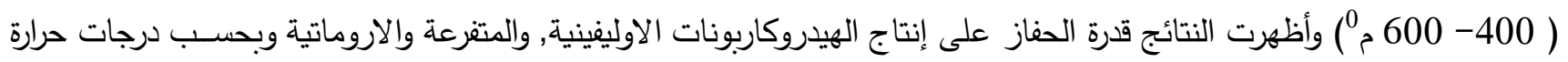

(8). المعاملة

وقام (عبدالله ) بدراسة تحضير حفاز من البلاتين المحمول على الالومينا المتعادلة من نوع الفا في المعاملة الحفازية للكيروسين وقد اظهرت النتائج أن فاعلية الحفاز المحضر تعتمد بصورة رئيسية على درجة حرارة المعاملة ووقت التلامس مع بخار النموذج المعامل 
حيث لوحظ حدوث تفاعلات الازمرة للبارافينات المســتقيمة وتكوين المركبات الالوفينية في درجات الحرارة التي تتراوح بين (300-

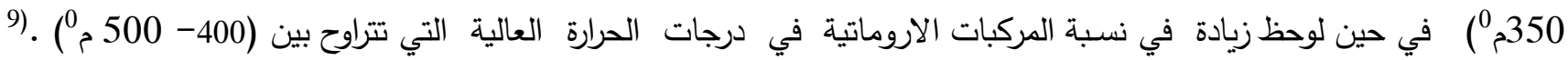

واستخدم (الجبوري ) خام البوكسـايت في انتاج الحفاز بعد اجراء بعض العمليات التكميلية على المادة الخام والحصـول على زيولايت

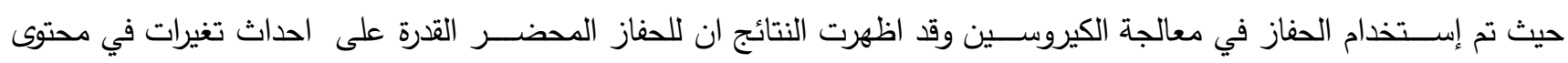

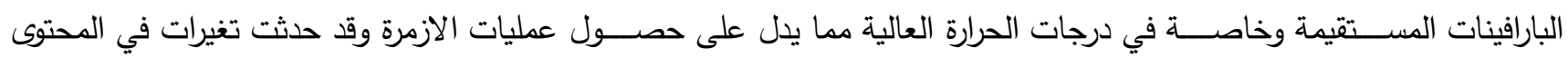

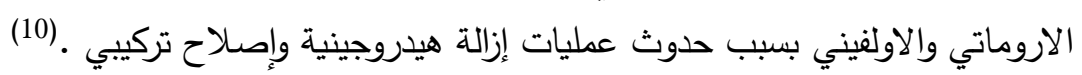
يهدف البحث الحالي الى تحضــير حفاز منخفض الكلفة من خلال اسـتغلال اطيان البوكسـايت الطبيعية والمتوافرة بكميات كبيرة في تلبي المناطق الغربية من العراق كمصدر للالومينا المتعادلة المستخدمة بوصفها مادة ساندة لحفاز البلاديوم واستخدام الحفاز المحضر في لئي المعالجة الحفازية للكيروسين

Preparation of the Sample for Study

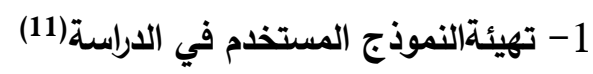
تم أخذ وزن معين من خام البوكسايت المتواجد في منطقة الحسينيات بمحافظة الانبار ويطحن بهاون يدوي ثم يغربل باستخدام منذل

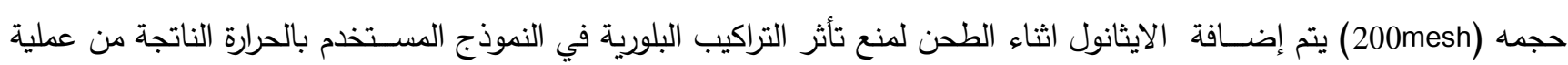
الطحن.

2- تحضيرحفاز الفا الومينا من خام البوكسايت (12 - 13 ) Preparation of Catalyst alpha alumina from Bauxite Ore

يوزن ( 50) غرام من خام البوكسايت بعد ازالة الكاربونات والسيليكا غير البلورية (تم إزالة الكاربونات عن طريق التصعيد الحراري مع حامض الهيدروكلوريك بتركيز 10\% في حين حين تم إزالة الســـيكيكا غير البلورية بعملية التصـــعيد الحراري مع محلول (0.5) مولاري

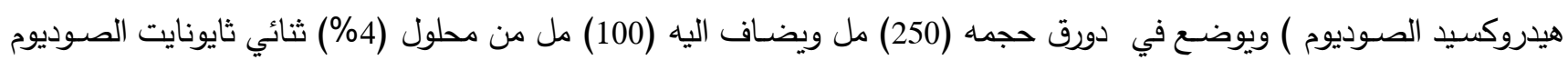
ويجرى التصـعيد الحراري لمدة ثلاث سـاعات بإسـتخدام مكثف عاكس، ثم يبرد الدورق إلى درجة حرارة الغرفة ثم يرشـح الراسب ويغسل بالماء المقطر ويعامل مع (50 ) مل حامض الهيدروكلوريك(0.05N ) ثم تجري عملية التصعيد الحراري لمدة ( 4 ) سـاعات بواسطة مكثف عاكس ويترك الدورق ليبرد إلى درجة حرارة الغرفة ثم يرشـح الراسب و يغسل باءل بالماء المقطر ويجفف في فرن كهربائي بدرجة حرارية ( 120مم) لمدة ( 5 ) ســـاعات ثم يبرد بدرجة حرارة الغرفة بعدها يضـــــاف إليه (75) مل من ثنائي كبريتيد

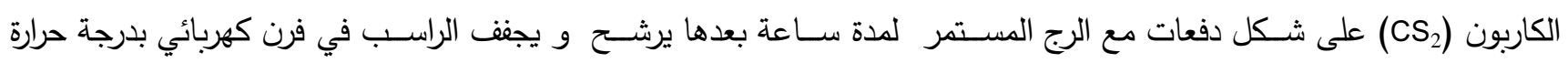
(120م'0) لمدة (3 ) سـاعات ثم ينقل الى بيكر سـعة (250) مل ويضـاف اليه (50) مل من حامض الكبريتيك المركز قطرة - قطرة ويرج الخليط ميكانيكياً مع إستخدام مكثف عاكس لمدة (4) ساعات بدرجة (110م'0) ثم يترك ليستقر لمدة (24) ساعة ويرشح المحلول

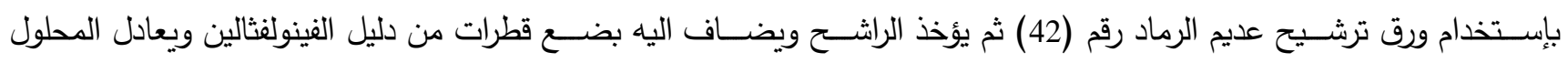
بإستخدام هيدروكسيد الأمونيوم (25 \% ) قطرة - قطرة مع التحريك المستمر الى ان يصبح لون الدليل بالون الوردي الفاتح ويسخن الخليط إلى درجة الغليان لمدة ( 5 ) دقائق ثم يترك الراسب لمدة ( 15) دقيقة ليستقر ويرشح بواسطة ورق ترشيح عديم الرماد رقم (

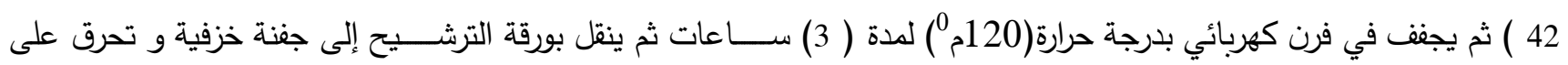

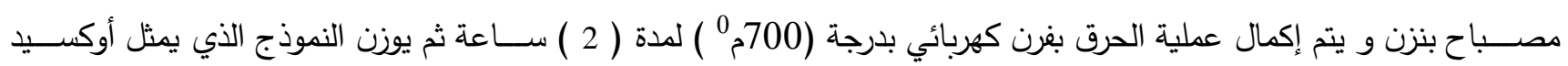
الالمنيوم من نوع الفا (الالومينا). 
3- 3 تحميل حفاز البلاديوم المحمل على الفا الومينا (14-15)

Preparation of catalyst pd on $\alpha-\mathrm{Al}_{2} \mathrm{O}_{3}$

يؤخذ ( 25 ) غرام من الالومينا المحضـرة من الفقرة السـابقة في دورق دائري سـعته (500 ) مل ويضـاف إليه ( 1 ) غرام من محلول

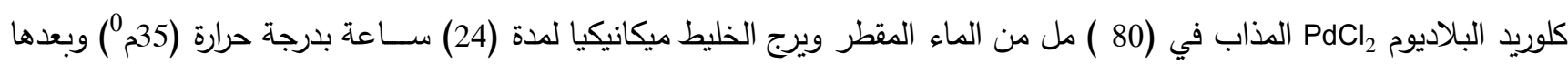
يضاف إليه (1) مولاري من محلول كاربونات الصوديوم Na $_{2} \mathrm{NaO}_{2} \mathrm{CH}_{3}$ - قطرة مع التحريك المستمر لحين وصول الدالة الهيدروجينية

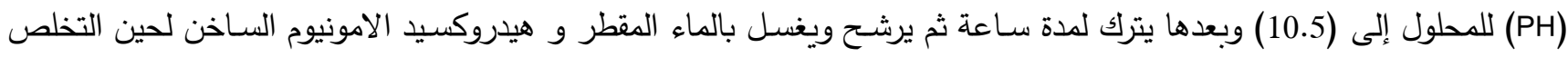

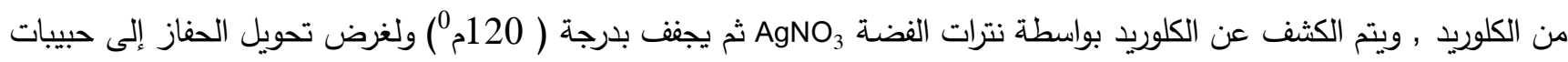
يتم نقله إلى بيكر ســته (250 )مل ويضــاف إليه كمية مناسـبة من الماء المقطر وبعدها ينقل إلى محقنة مناسـبة مســيطر عليها للحصول على الثكل الحبيبي ومن ثم يترك على زجاج الساعة لمدة (24 ) سـاعة بدرجة حرارة المختبر وبعدها يجفف بفرن كهربائي إئي

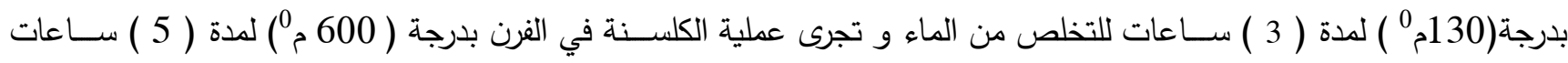

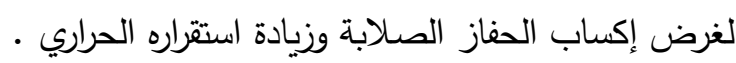

Gravimetric analysis (TGA)

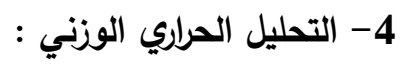

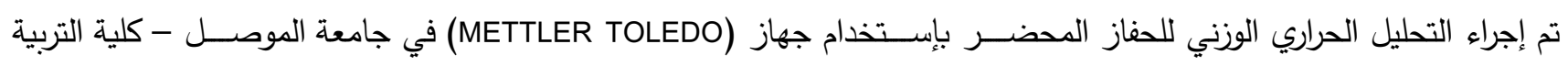
الاساسية قسم العلوم.

\section{X-ray Diffraction}

5- قياس حيود الاشعة السينية لغرض التعرف على أنماط حيود التركيب البلوري وتقدير النسبة المئوية للعناصر المختلفة لكل من خام البوكسايت والحفاز المحضر تم إجراء قياس تثتت الطاقة بالاشعة السينية في جامعة طهران - جمهورية إيران الإسلامية .

\section{X-ray Fluorescence}

6- قياس الاثعة السينية المتفلورة

بعد التعرف على أنماط الحيود للعناصر المختلفة لخام البوكسايت والحفاز تم تقدير نسبة هذه العناصر بهيئتها الاوكسيدية من خلال قياس فلورة الاشعة السينية وتم إجراء القياس في جامعة طهران - جمهورية إيران الإسلامية .

\section{Catalytic treatments carried out on kerosene}

$$
\text { 7- المعالجات الحفازية التي أجريت على الكيروسين }
$$

Stainless steel( نضع ( 50) مل من الكيروسين في مفاعل الاوتوكليف المحكم الغلق والمصنوع من مادة الفولاذ المقاوم للصداً

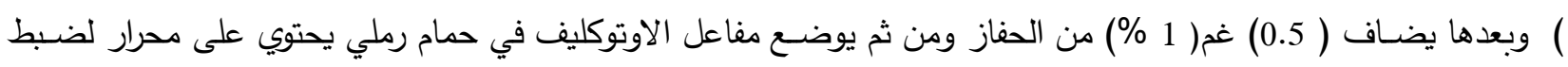

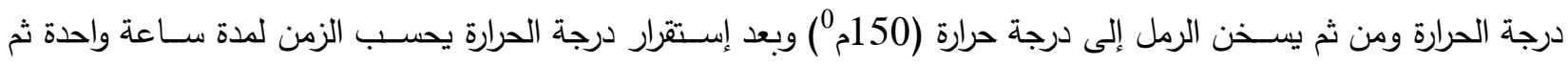

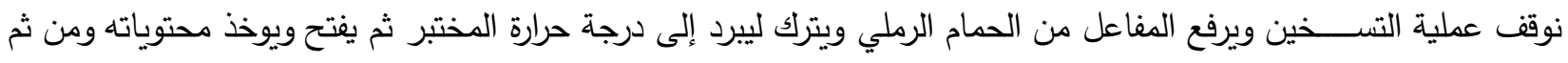

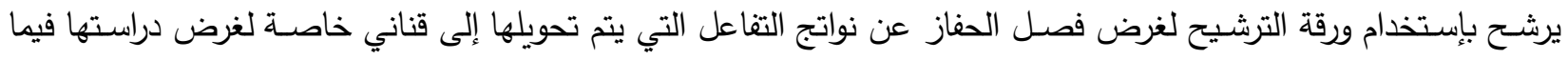

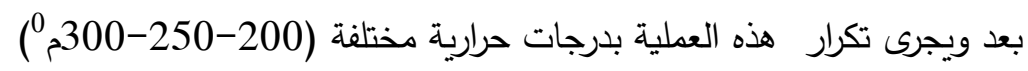
8 - تحديد الظروف المثلى للمعاملة الحفازية بعد تحليل النماذج الناتجة من المعاملة الحفازية طيفيا وكيميائيا تبين أن أفضل درجة حرارة كانت عند (250مج م) حيث تم تثبيتها وتغيير زمن التفاعل إلى (2 ساعة ) ونسبة حفاز (2\%) وزنا للتعرف على نوع التغيرات تحت الظروف الجديدة . 
9- الدراسات التي أجربت على الكيروسين (الام ) والمعامل حفازيا :

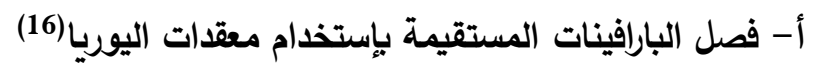

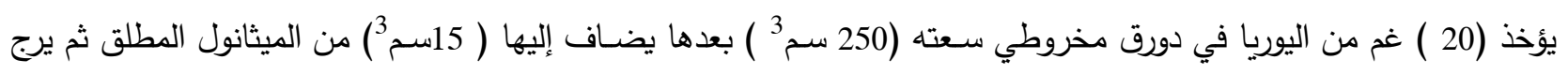

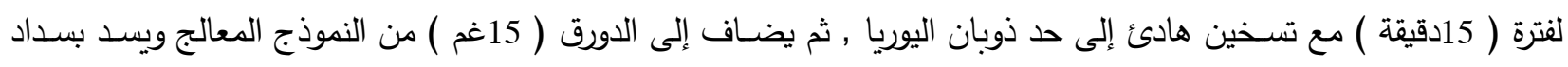

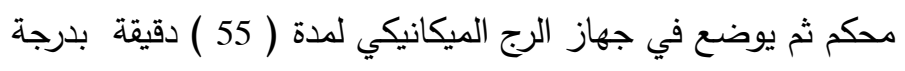

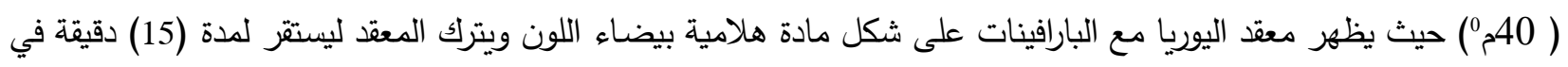
ماء بارد ثم يرشح بإستخدام ورق ترشيح عديم الرماد رقم (42) ثم يغسل المعقد المتكون جيدا بالميثانول المطلق البارد ثم يترك لئك

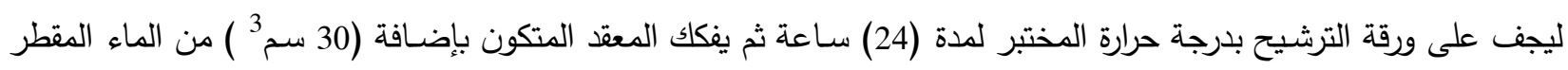

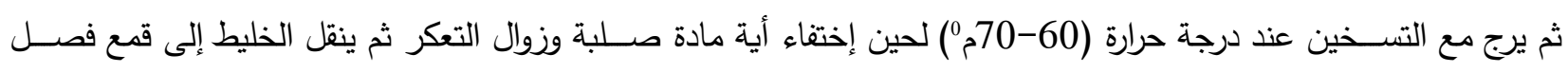

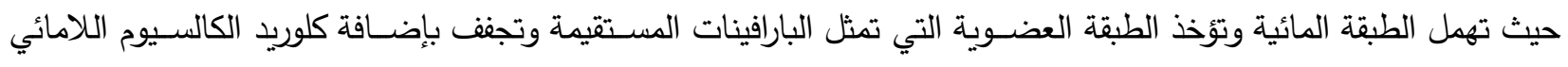
وتوزن وتحسب نسبتها المؤية.

ب- تقدير نسبة المركبات الاروماتية والاوليفينية بإستخدام حامض الكبريتيك المركز (17) (10) يؤخذ (10) غم من النموذج المعالج في دورق سعة ( 50 سم3 ) ثم يضاف إليه ( 10 غم ) من حامض الكبريتيك المركز قطرة -

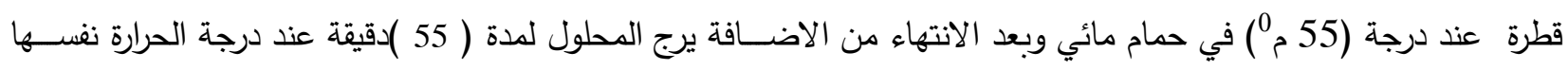

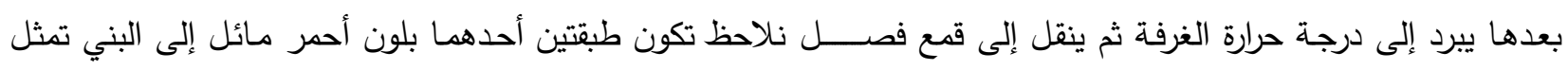

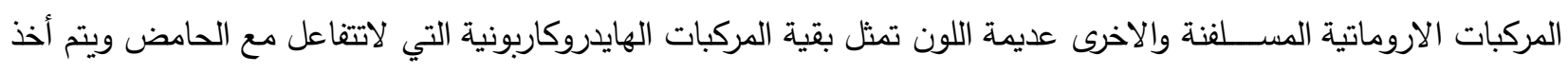

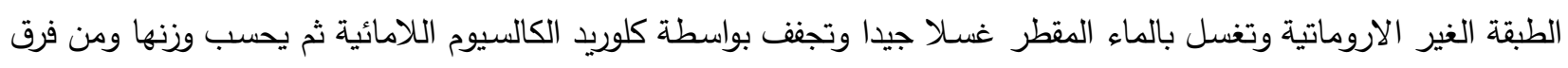

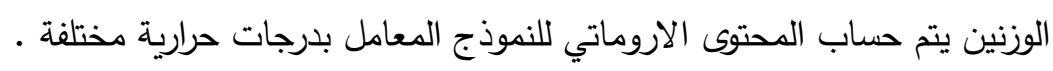
ج- قياس طيف الاشعة تحت الحمراء تم قياس طيف الاثـعة تحت الحمراء لغرض التعرف على طبيعة التغيرات التركيبية للكيروسين بعد إجراء المعاملة الحفازية وتم

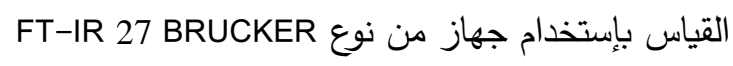

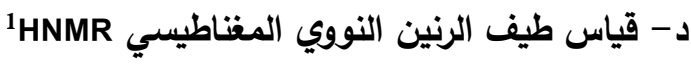

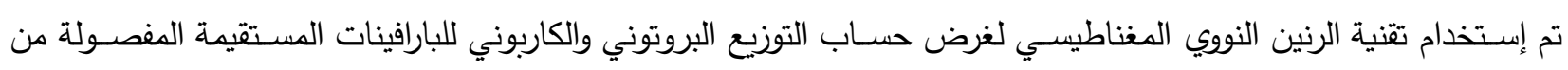

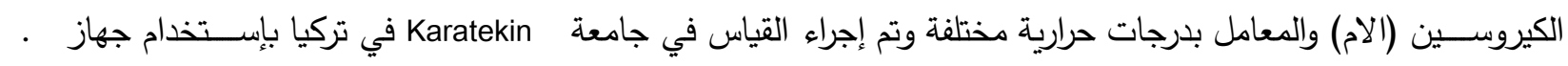

$600 \mathrm{MHz}$ of Agilent brand

النتائج والمناقشة :

تؤدي الحفازات دورا مهما في انتاج المواد الاساسية في الصناعات البتروكيمياوية وكذلك دورها الهام في عمليات التكرير النفطي مما ادى إلى زيادة الطلب عليها وارتفاع اسعارها وبهذه الدراسة استعمل خام البوكسايت الذي يعد من الخامات الطبيعية المتوفرة

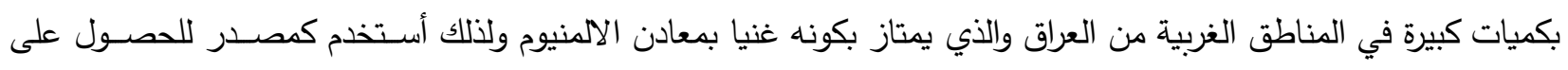

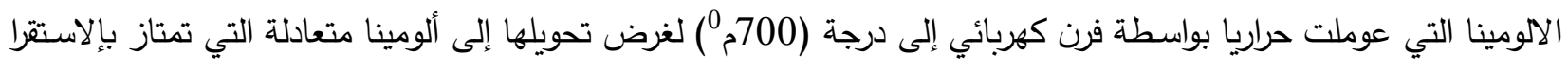

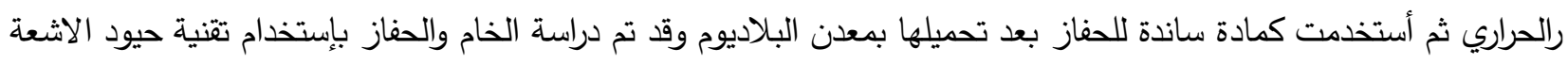

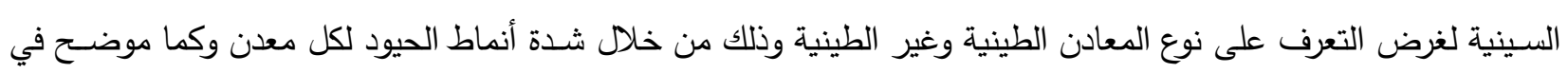

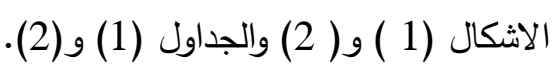




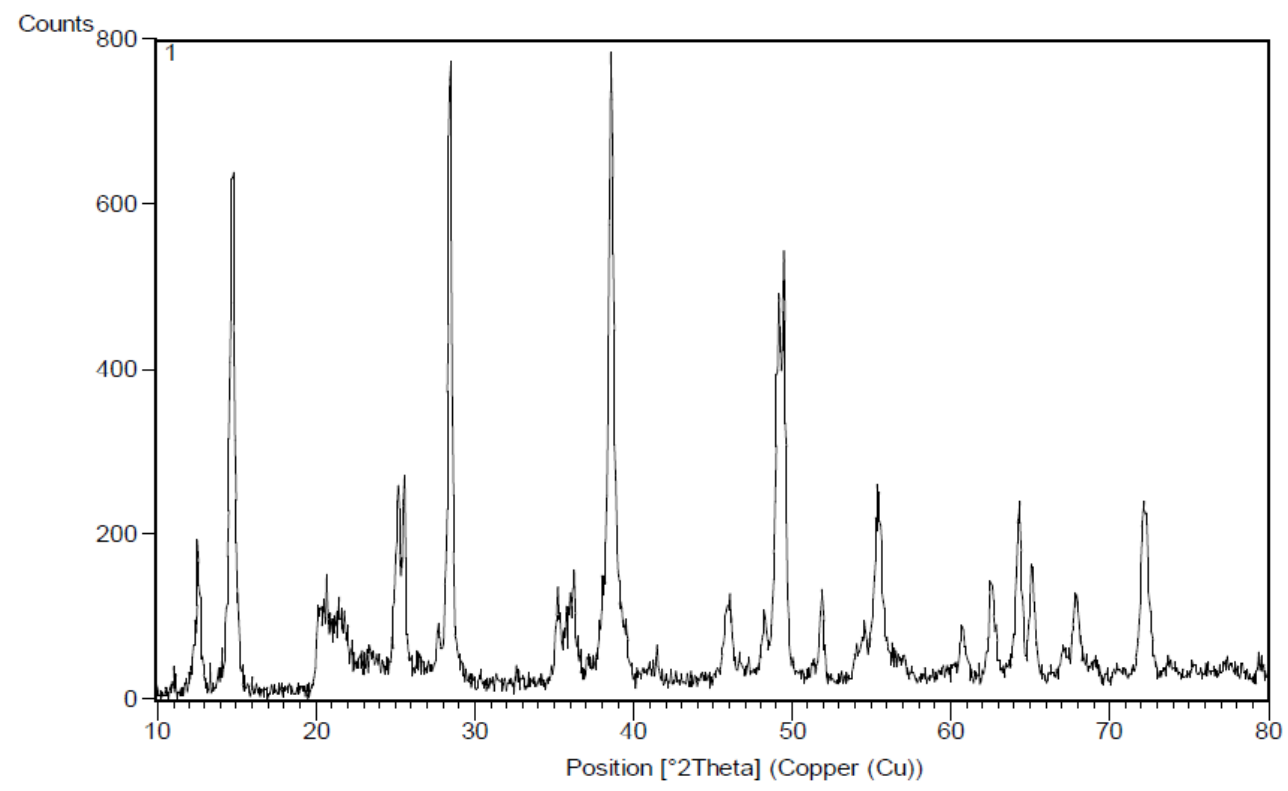

الثكل (1): يوضح أنماط حيود الاشعة السينية للخام

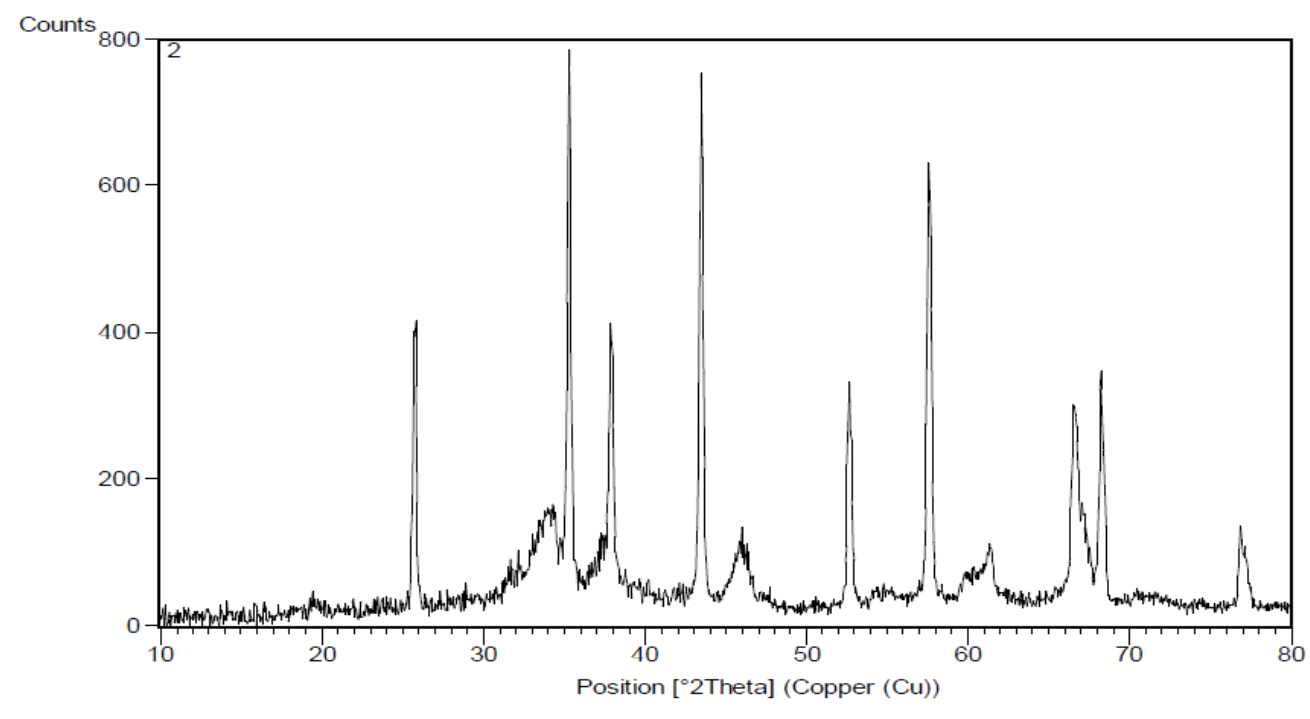

الثكل (2): حيود الاشعة السينية(XRD) للحفاز

ويمكن توضيح قيم المسافات الذريه(d-spacing) والزوايا (20) بالجدول(1 ) 
Journal of Education and Science (ISSN 1812-125X), Vol: 30, No: 1, 2021 (126-140)

الجدول(1): قيم المسافات الذريه (d-spacing) والزوايا (20) للمعادن التي ظهرت في حيود الاثعة السينية لذام البوكسايت.

\begin{tabular}{|c|c|c|c|c|}
\hline minerals & $2 \theta$ & d-spacing & $\begin{array}{c}\text { Peak } \\
\text { Intensity }\end{array}$ & I/I1 \\
\hline \multirow{3}{*}{ Boehmite } & 14.7 & 6.013 & 635.1 & 81.39 \\
& 28.4 & 3.137 & 780.8 & 100 \\
& 38.5 & 2.334 & 773.3 & 99.10 \\
\hline \multirow{2}{*}{ Gibbsite } & 49 & 1.856 & 383.9 & 49.20 \\
\hline & 20.1 & 4.405 & 98.2 & 12.60 \\
& 36.2 & 2.478 & 121.3 & 15.55 \\
\hline \multirow{3}{*}{ Kaolinite } & 12.6 & 7.022 & 139.3 & 17.86 \\
& 21.6 & 4.113 & 66.1 & 8.47 \\
& 25.1 & 1.540 & 221.3 & 28.36 \\
& 55.9 & 1.973 & 84.5 & 10.83 \\
\hline \multirow{2}{*}{ Quartz } & 55.3 & 1.659 & 110.1 & 14.12 \\
\hline \multirow{2}{*}{ Calcite } & 67.8 & 1.380 & 219.4 & 10.69 \\
& 60.7 & 1.524 & 83.4 & 7.66 \\
& 64.3 & 1.448 & 59.7 & 27.67 \\
Hematite & 65.1 & 1.432 & 122.8 & 15.66 \\
\hline & 69.4 & 1.841 & 502.5 & 14.40 \\
& 72 & 1.485 & 113.7 & 23.44 \\
\hline
\end{tabular}

حيث نلاحظ من الثـكل (1)والجدول(1)ان خام البوكسـايت قيد الدراســة يتكون بصــوره رئيسـهـ من اكاسـيد الالمنيوم المائية وهي وهي البوهمايت والجبسـايت فظلا عن الكاؤولينات والهيميتات والكالسـايت وهذا يتوافق مع نتائج التحليل الكيميائي التي اجريت على الخام ذاته في دراسات سابقه (13)مما يؤكد احتوائه على نسبه عالية من الالمنيوم بهيئته الاوكسيدية. وعند قياس حيود الاثــعة الســينية للحفاز المحضــر والمتكون من البلاديوم المحمول على الالومينا المتعادلة من نوع الفا

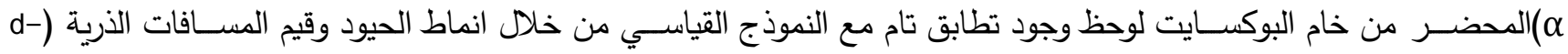
(spacing والزوايا (20) لكل منها مع ظهور حزم ضــــيفة تعود للبلاديوم بهيئته الاوكســـيدية عند قيم (20)على النحو التالي (68.1,54.8,40.1,34.7)

الجدول(2): قيم المسافات الذرية (d-spacing) والزوايا(20) للحفاز المتكون من الالومينا المتعادلة ومقارنتها مع النموذج القياسي •

\begin{tabular}{|c|c|c|c|}
\hline $\begin{array}{c}\text { Standard Alumina } \\
\text { From Literatures } \\
(2 \theta)\end{array}$ & $\begin{array}{c}\text { Prepared Alumina From X-ray } \\
\text { Chart } \\
(2 \theta)\end{array}$ & $\begin{array}{c}\text { d-spacing } \\
(\mathrm{A})\end{array}$ & $\mathrm{I} / \mathrm{I}_{1}$ \\
\hline 43.29 & 43.29 & 2.09 & 100 \\
\hline 35.16 & 35.29 & 2.55 & 99 \\
\hline 57.60 & 57.59 & 1.60 & 82.7 \\
\hline 25.59 & 25.73 & 3.48 & 52.2 \\
\hline 37.96 & 37.91 & 2.37 & 46.8 \\
\hline 68.48 & 68.39 & 1.37 & 43.8 \\
\hline 52.59 & 52.60 & 1.73 & 39.8 \\
\hline 66.82 & 66.76 & 1.40 & 30.3 \\
\hline 76.88 & 76.86 & 1.23 & 15.1 \\
\hline
\end{tabular}


قياس فلورة الاشعة السينية لكل من خام البوكسايت والحفاز المحضر Measarement of $\mathbf{X}$ - ray Fluorescence for Bauxite ore and Catalytic prepared بعد التعرف على النسـب المئوية للمعادن المكونة لخام البوكسـايت والحفاز بطريقة تثـت الطاقة بالاشـعة السينية (EXD) تم تقدير

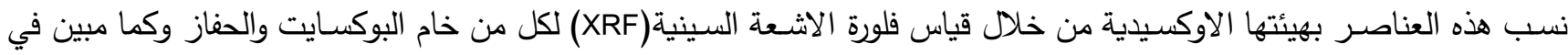

الجداول (3 ) و (4) (4) (4)

الجدول (3): النسب المئوية للعناصر الموجودة في خام البوكسايت بهيئتها الاوكسيدية عن طريق قياس فلورة الاشعة السينية .

\begin{tabular}{|c|c|}
\hline Oxides & Wt (\%) \\
\hline $\mathrm{Al}_{2} \mathrm{O}_{3}$ & 59.29 \\
\hline $\mathrm{SiO}_{2}$ & 23.18 \\
\hline $\mathrm{TiO}_{2}$ & 8.35 \\
\hline $\mathrm{Fe}_{2} \mathrm{O}_{3}$ & 2.22 \\
\hline $\mathrm{CaO}$ & 0.6 \\
\hline $\mathrm{MgO}$ & 0.76 \\
\hline $\mathrm{Na}_{2} \mathrm{O}$ & 0.54 \\
\hline
\end{tabular}

نلاحظ من الجدول ( 3) إحتواء خام البوكسايت على نسبة عالية من أكاسيد الإمنيوم والسليكون مما يدل على تكونه بصورة رئيسية

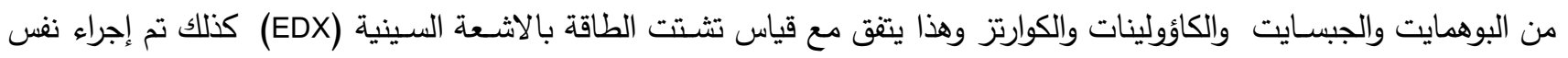

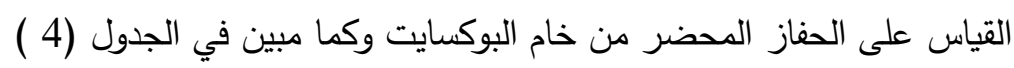

الجدول (4): النسب المئوية للعناصر الموجودة في الحفاز المحضر بهيئتها الاوكسيدية عن طريق قياس فلورة الاشعة السينية

\begin{tabular}{|c|c|}
\hline Oxides & Wt (\%) \\
\hline $\mathrm{Al}_{2} \mathrm{O}_{3}$ & 85.93 \\
\hline $\mathrm{SiO}_{2}$ & 1.16 \\
\hline $\mathrm{TiO}_{2}$ & 0.48 \\
\hline $\mathrm{Fe}_{2} \mathrm{O}_{3}$ & 1.38 \\
\hline $\mathrm{CaO}$ & 4.34 \\
\hline $\mathrm{MgO}$ & 0.39 \\
\hline $\mathrm{Na}_{2} \mathrm{O}$ & 0.55 \\
\hline $\mathrm{PdO}$ & 0.99 \\
\hline
\end{tabular}

حيث نلاحظ من الجدول ( 4) إرتفاع في نسبة أوكسيد الالمنيوم نسبة (26.6) مع إنخفاض واضـح في نسبة (السيليكا) بنسبة (22\%) والتي تؤثر سلبا على جودة الحفاز وقدرته التحفيزية وهذا يتوافق مع قياس تشتت الطاقة بالاشعة السينية (EDX)

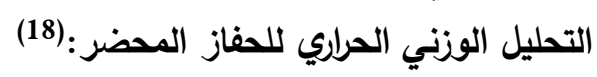
تم اجراء قياس التحليل الحراري الوزني للحفاز المحضــر لغرض معرفة مدى اسـتقراره الحراي عند تعرضــــ لدرجات حرارة مختلفة

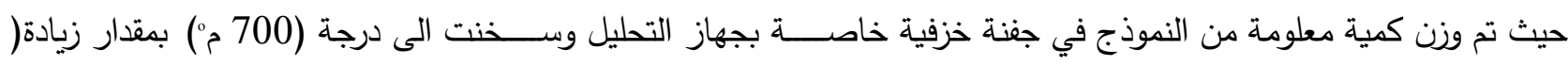

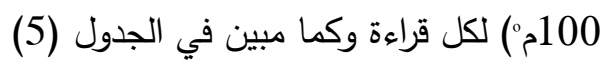




\begin{tabular}{|c|c|}
\hline \multicolumn{2}{|c|}{ الجدول (5): } \\
\hline Temperature & Lossin Weight \% \\
\hline 0 & 0.00 \\
\hline 100 & 0.47 \\
\hline 200 & 0.94 \\
\hline 300 & 1.15 \\
\hline 400 & 1.3 \\
\hline 500 & 1.4 \\
\hline 600 & 1.46 \\
\hline 700 & 1.46 \\
\hline
\end{tabular}

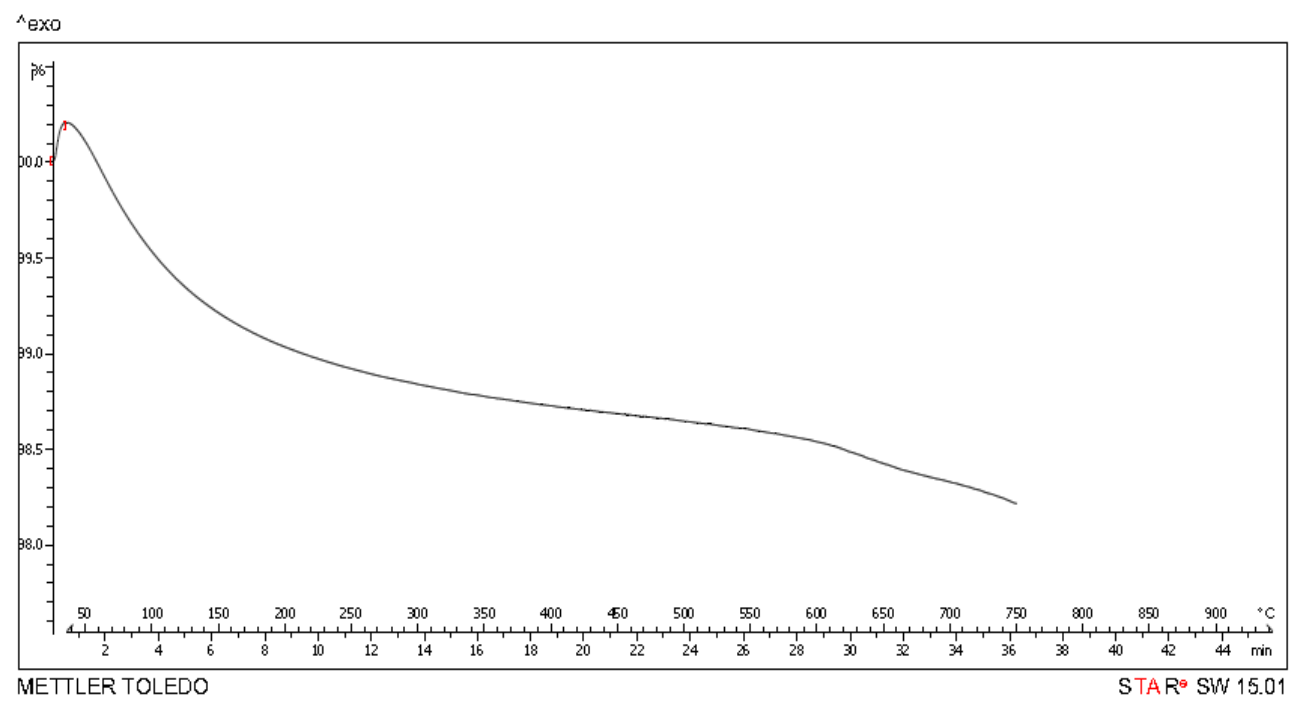

الثكل (3): منحنى التحليل الوزني الحراري للحفاز المحضر

في الجدول (5) والثكل (3) لوحظ أن الحفاز عند درجة حرارة ( 100م ${ }^{0}$ ) يفقد من وزنه (0.47 \%) بســبب فقدان جزيئات

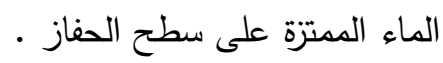

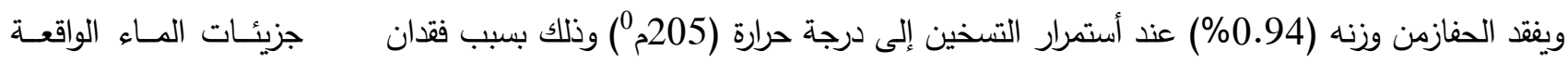

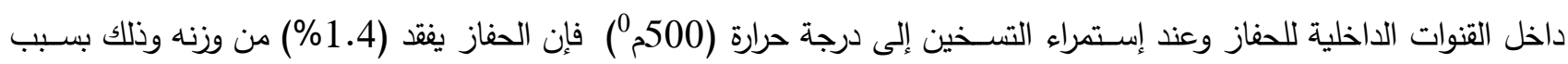
فقدان مجاميع الهيدروكسيل الموجودة ضمن تركيب الحفاز ويلاحظ استقراره الحراري الى درجة حرارة (700حمّة) تحديد الظروف الملائمة للمعاملة الحفازيـة : تحدانة

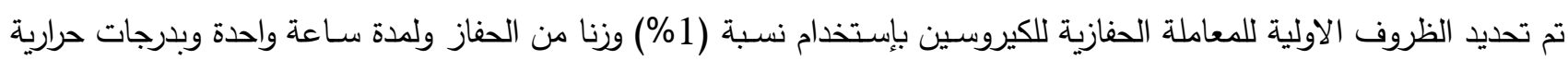

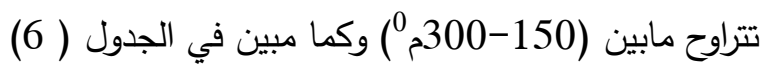

الجدول (6): الظروف والنتائج الاولية للمعاملة الحفازية للكيروسين

\begin{tabular}{|c|c|c|c|c|c|c|c|c|}
\hline Sample & Temp ${ }^{0} \mathrm{C}$ & $\begin{array}{c}\text { Reaction } \\
\text { Tim (hrs.) }\end{array}$ & $\begin{array}{c}\text { Catalyst } \\
\text { Ratio(\%) }\end{array}$ & $\begin{array}{c}\text { n-Paraffin } \\
(\%)\end{array}$ & $\begin{array}{c}\text { Aromatic } \\
\text { +Olefin } \%\end{array}$ & $\begin{array}{c}\text { Other* } \\
\text { Comp. }\end{array}$ & $\begin{array}{c}\text { Density } \\
\mathrm{gm} \mathrm{cm}^{3}\end{array}$ & $\begin{array}{c}\text { Refractive } \\
\text { Index }\end{array}$ \\
\hline $\begin{array}{c}\text { Kerosene } \\
\text { Iال }\end{array}$ & $\ldots$ & $\ldots$ & $\ldots$ & 39.5 & 15.4 & 45.1 & 0.786 & 1.409 \\
\hline & 150 & 1 & 1 & 36.5 & 19.2 & 44.3 & 0.788 & 1.408 \\
\hline & 200 & 1 & 1 & 34.1 & 22.8 & 43.1 & 0.791 & 1.412 \\
\hline & 250 & 1 & 1 & 26.4 & 31.6 & 42 & 0.833 & 1.416 \\
\hline & 300 & 1 & 1 & 31.9 & 11.5 & 56.6 & 0.782 & 1.406 \\
\hline
\end{tabular}

*المركبات البارافينية المتفرعة والنفثينية 
نلاحظ من الجدول (6) إنخفاض في نسبة البارافينات المستقيمة مع إرتفاع ملحوظ في نسبة المركبات الاروماتية والاوليفينية بالاخص

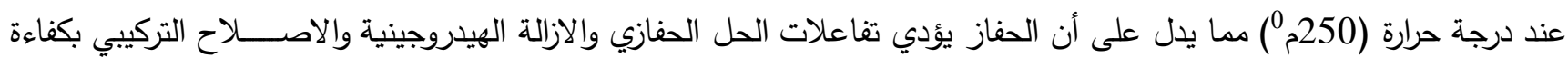

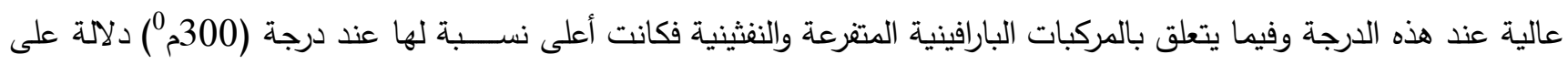
حدوث تفاعلات التحولق والازمرة .

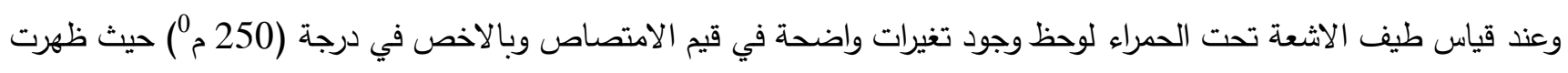

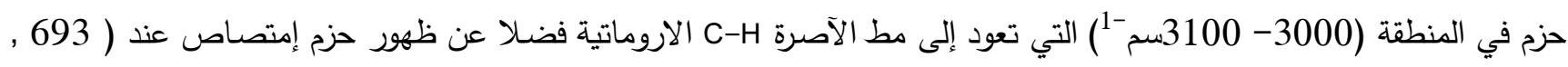

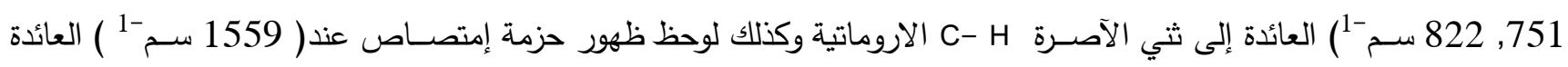
إلى C=C للنظام الاروماتي وظهورحزم إمتصـاص عند ( 1461 C وتكوين الاوليفينات .

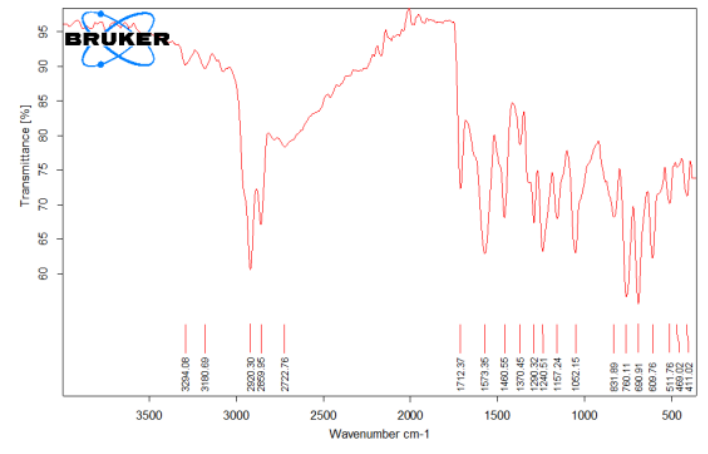

الثكل (5): طيف IR للكيروسين المعامل عذ (150م0)

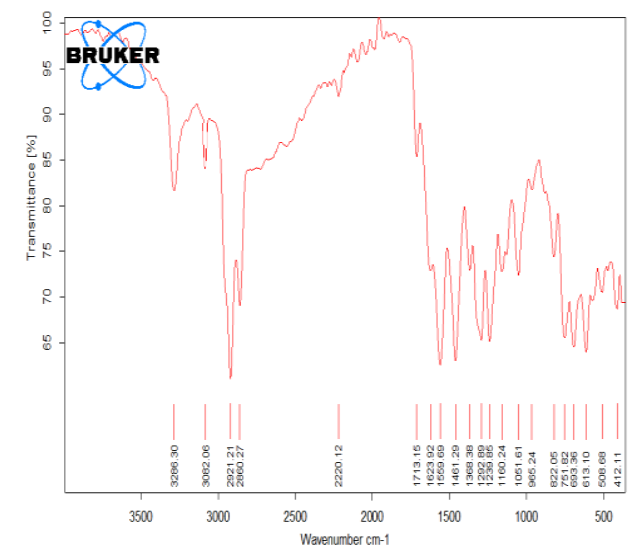

الثكل (7): طيف IR للكيروسين المعامل عند ( 250م )

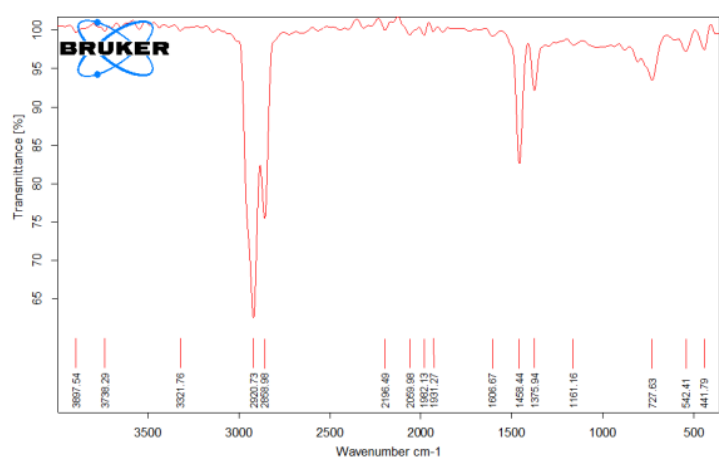

الثكل (4): طيف IR للكيروسين الام

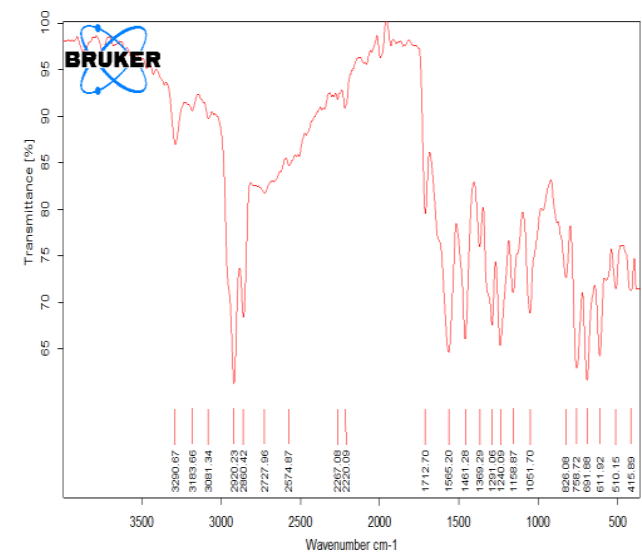

الثكل (6): طيف IR للكيروسين المعامل عند ( 200 م0 ) 


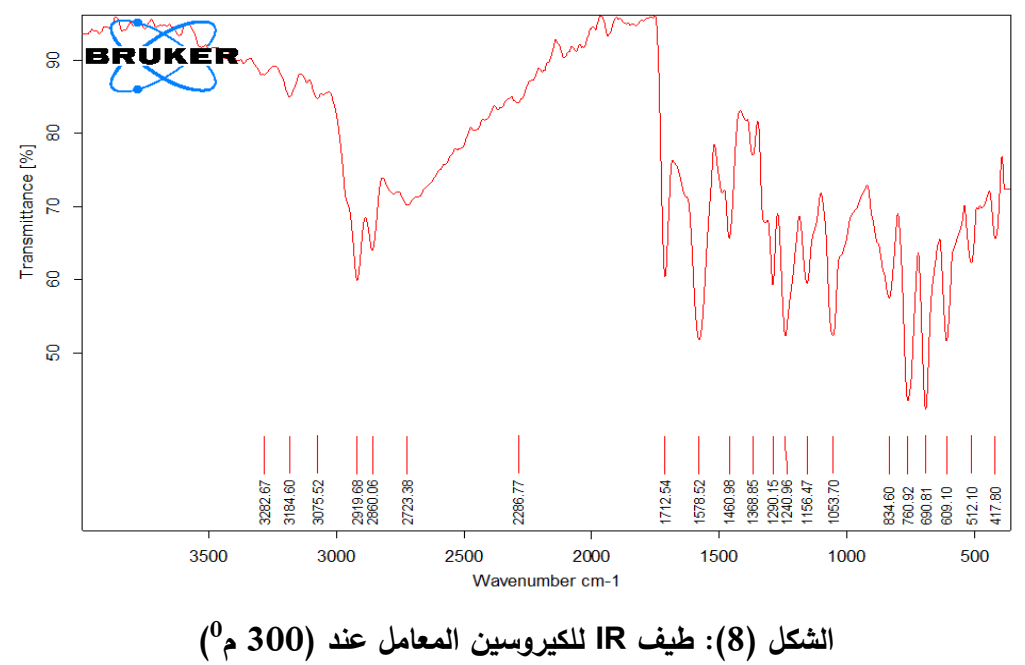

بعد تثبيت درجة الحرارة عند (250م0) تم تغيير نسبة الحفاز إلى (2\%) وزمن تفاعل إلى (2و3ساعة) وكما مبين في الجدول (7)

الجدول(7): الظروف والنتائج المصصل عليها بع تغيير كل من نسبة الحفاز وزمن التفاعل

\begin{tabular}{|c|c|c|c|c|c|c|c|c|}
\hline Sample & $\underset{{ }^{0} \mathrm{C}}{\text { Temp }}$ & $\begin{array}{l}\text { Reaction } \\
\text { Tim (hrs.) }\end{array}$ & $\begin{array}{c}\text { Catalyst } \\
\text { Ratio(\%) }\end{array}$ & $\begin{array}{c}\text { n-Paraffin } \\
(\%)\end{array}$ & $\begin{array}{l}\text { Aromatic } \\
+ \text { +Olefin } \%\end{array}$ & $\begin{array}{l}\text { Other* } \\
\text { Comp. }\end{array}$ & $\begin{array}{l}\text { Density } \\
\mathrm{gm} / \mathrm{cm}^{3}\end{array}$ & $\begin{array}{l}\text { Refractive } \\
\text { Index }\end{array}$ \\
\hline Kerosene & $\ldots$ & $\ldots$ & $\ldots$ & 39.5 & 15.4 & 45.1 & 0.786 & 1.409 \\
\hline & 250 & 1 & 2 & 18.2 & 32.8 & 49 & 0.79 & 1.411 \\
\hline & 250 & 2 & 2 & 12.1 & 41.6 & 46.3 & 0.88 & 1.42 \\
\hline & 250 & 3 & 2 & 15.4 & 34.5 & 50.1 & 0.82 & 1.41 \\
\hline
\end{tabular}

يتضح من الجدول (7) أن زيادة نسبة الحفاز إلى (2\%) أدى إلى حصول تغيرات واضحة في نسبة المركبات الهيدروكاربونية حيث نلاحظ إنخفاض في نسـبة المركبات البارافينية المسـتقيمة وإرتفاع في نسـبة المركبات الاروماتية والاوليفينية يرافقها ارتفاع في قيم

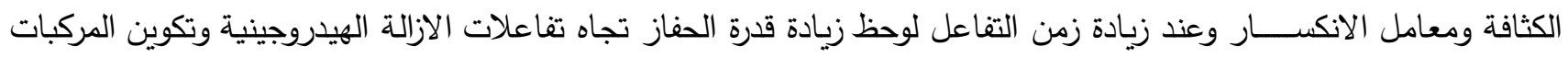

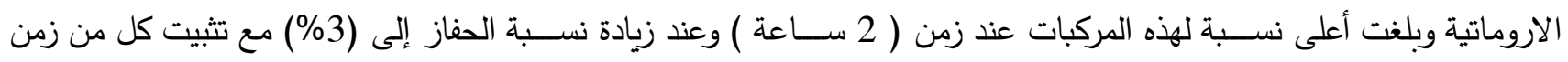

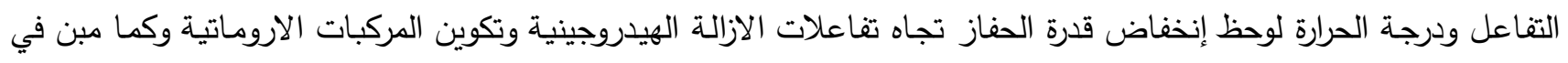

الجدول (8) (18) (20)

الجدول (8): الظروف والنتائج المحصل عليها بعد تغيير نسبة الحفاز إلى (3\%)

\begin{tabular}{|c|c|c|c|c|c|c|c|c|}
\hline Sample & $\begin{array}{l}\text { Temp } \\
{ }^{0} \mathrm{C}\end{array}$ & $\begin{array}{c}\text { Reaction } \\
\text { Tim (hrs.) }\end{array}$ & $\begin{array}{l}\text { Catalyst } \\
\text { Ratio(\%) }\end{array}$ & $\begin{array}{c}\text { n-Paraffin } \\
(\%)\end{array}$ & $\begin{array}{l}\text { Aromatic } \\
+ \text { +Olefin } \%\end{array}$ & $\begin{array}{l}\text { Other* } \\
\text { Comp. }\end{array}$ & $\begin{array}{l}\text { Density } \\
\mathrm{gm} / \mathrm{cm}^{3}\end{array}$ & $\begin{array}{l}\text { Refractive } \\
\text { Index }\end{array}$ \\
\hline Kerosene & $\ldots$ & $\ldots$ & $\ldots$ & 39.5 & 15.4 & 45.1 & 0.786 & 1.409 \\
\hline & 250 & 2 & 3 & 36.2 & 21.5 & 42.3 & 0.787 & 1.411 \\
\hline
\end{tabular}

بذلك يمكن الاسـتتـاج أن للحفاز المحضـر القدرة على إجراء تفاعلات الازالة الهيدروجينية والحل الحفازي والاصــلاح التركيبي من

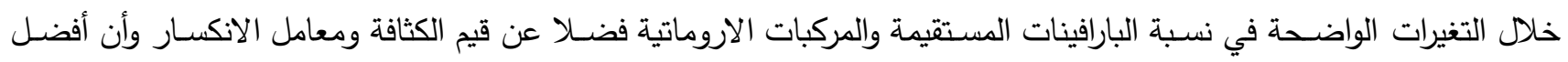

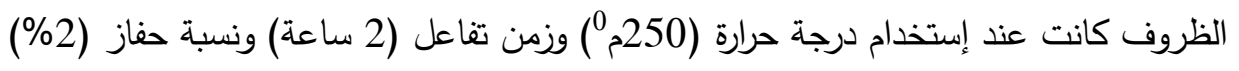
وتتم دراسة البارافينات المستقيمة المفصولة من الكيروسين الام والمعامل بدرجات حرارية مختلفة وحساب التوزيع البروتوني وكما مبين في وني الجدول (9) 
الجدول (9): يوضح التوزيع البروتوني النسبي للبارافينات المستقيمة المفصولة من الكيروسين الام والكيروسين الام المعامل بدرجات حرارة (150-

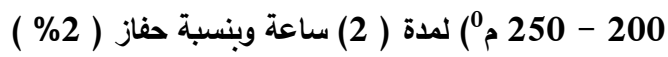

\begin{tabular}{|c|c|c|}
\hline n- paraffine & $\mathrm{H}_{\text {me }} \%$ & $\mathrm{H}_{\text {my }} \%$ \\
\hline Untreated Kerosene & 23.80 & 76.19 \\
\hline${ }^{0} \mathrm{C} 150$ & 27.92 & 72.07 \\
\hline${ }^{0} \mathrm{C} 200$ & 25.12 & 74.87 \\
\hline${ }^{0} \mathrm{C} 250$ & 27.18 & 72.816 \\
\hline
\end{tabular}

كما اشـتملت الدراسـة على تحليل البارافينات المسـتقيمة المفصـولة من الكيروسـين الأم والمعامل بدرجات حرارية مختلفة (

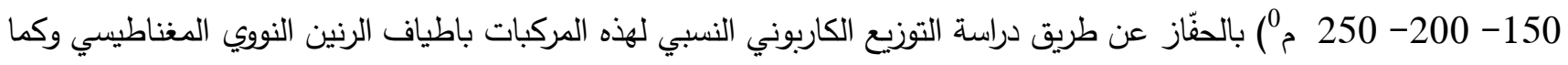
مبين في الجدول الآتي:

جدول (10): التوزيع الكاربوني النسبي للبارفينات المستقيمة المفصولة من الكيروسين الام والمعامل بدرجات حراية (150- 200 - 250 م²)

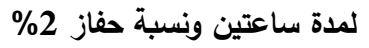

\begin{tabular}{|c|c|c|}
\hline n- paraffine & $\mathbf{C}_{\mathbf{~ m e ~}} \mathbf{\%}$ & $\mathbf{C}_{\mathbf{~ m y}} \mathbf{\%}$ \\
\hline Untreated Kerosene & 7.9 & 38.09 \\
\hline${ }^{0} \mathrm{C} 150$ & 9.30 & 36.03 \\
\hline${ }^{0} \mathrm{C} 200$ & 8.37 & 37.43 \\
\hline${ }^{0} \mathrm{C} 250$ & 9.06 & 36.40 \\
\hline
\end{tabular}

يتبين من الجدول ( 10) أن الكيروسـين الأم يحتوي على نسـبة من الأنظمة المثيلينية تسـاوي (7.9\%) ونسـبة من الأنظمة المثيلية تساوي (38.9\%) وعند معاملة الكيروسين بدرجات حرارية مختلفة (150-200-250م م) ) نلاحظ زيادة في نسبة المجاميع المثيلية وانخفاض في نســبة الأنظمة المثيلينية أي نقصـــان طول الســلســلـة لذلك من المتوقع حدوث بعض عمليات الحل الحفّازي وتحول

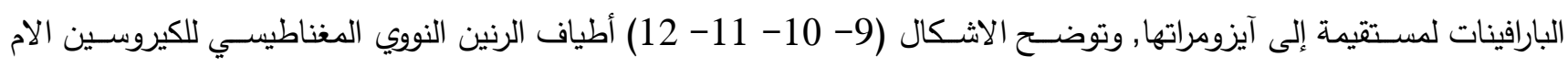

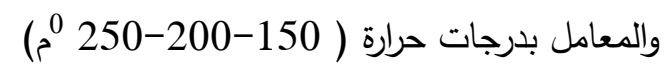

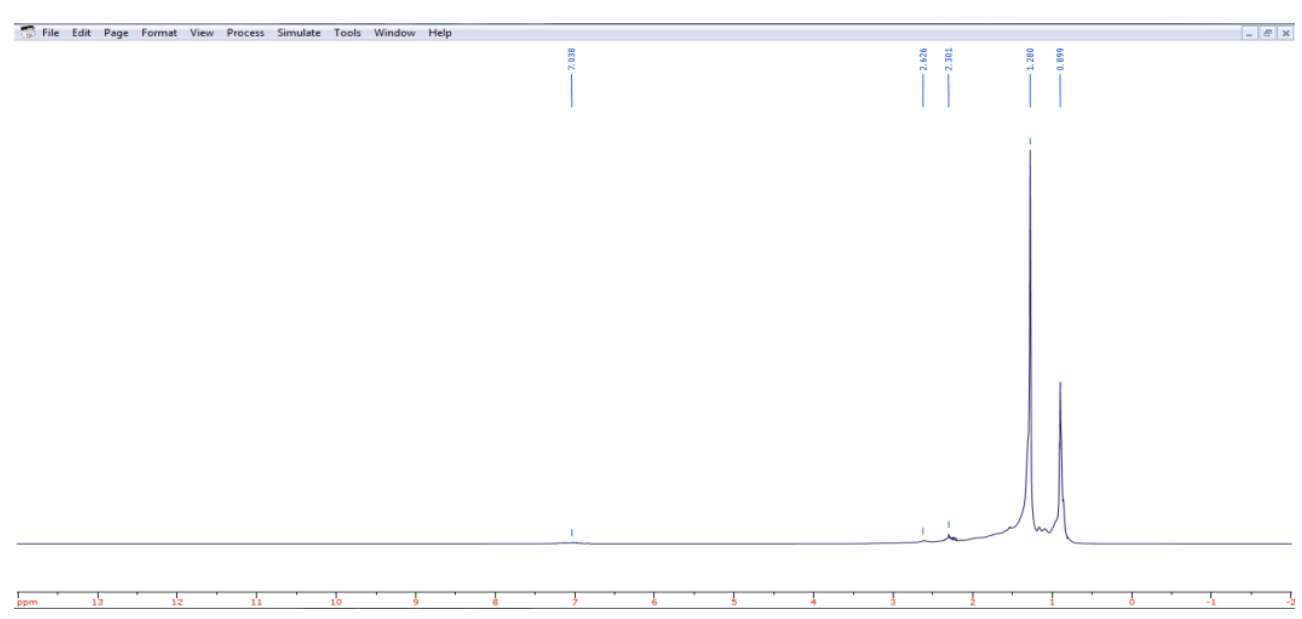

الثكل (9): طيف الرنين النووي المغناطيسي للبارافينات المستقيمة المفصولة للكيروسين الام 


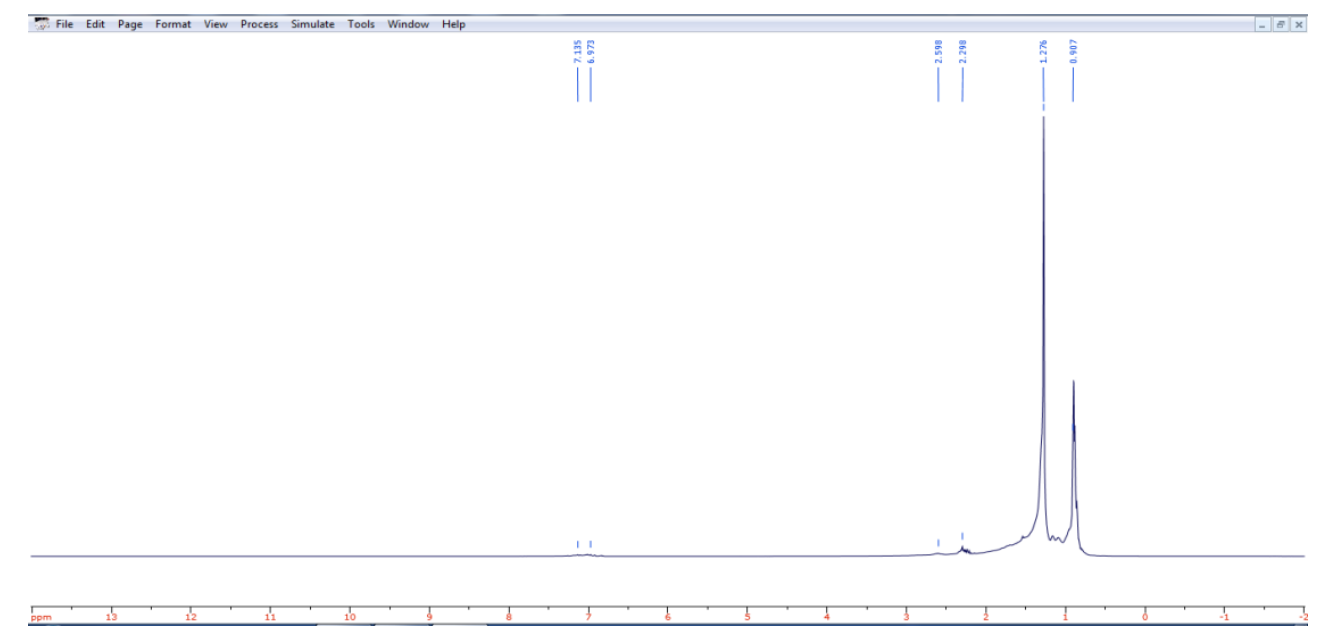

الثكل (10): طيف الرنين النووي المغناطيسي للبارافينات المستقيمة المفصولة للكيروسين المعامل بدرجة (150مم)

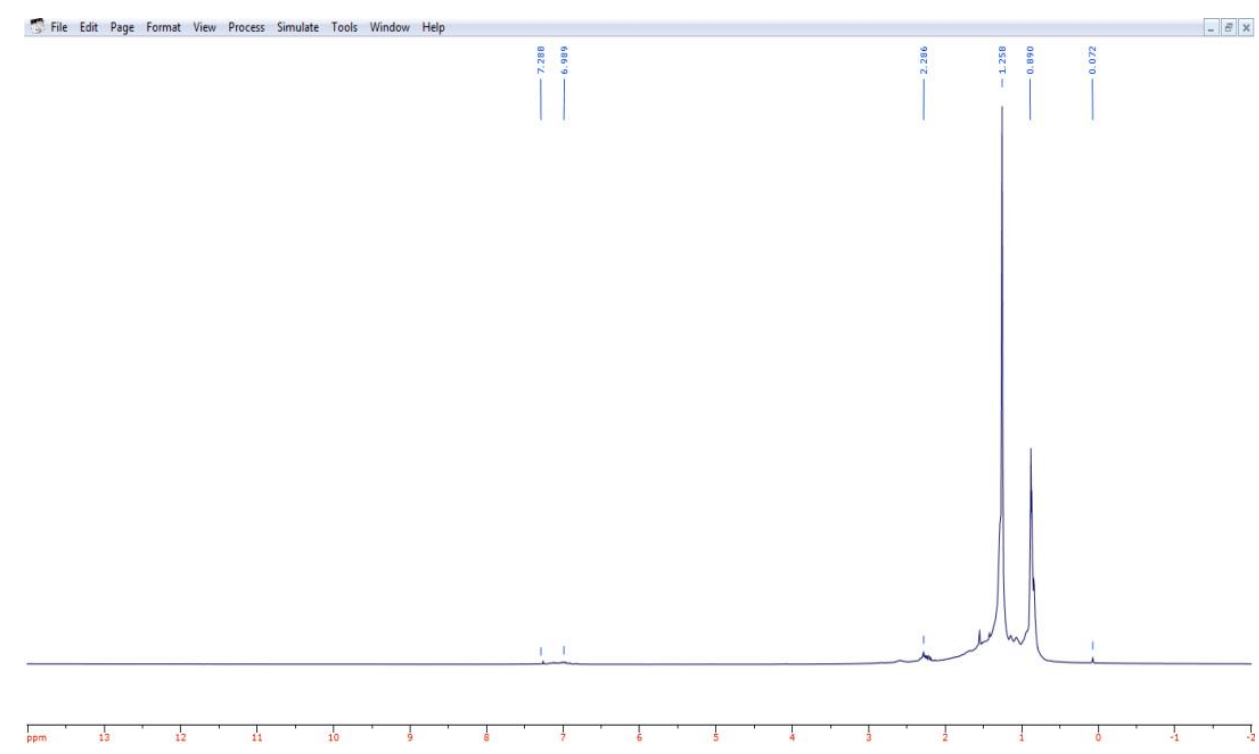

الثكل (11): طيف الرنين النووي المغناطيسي للبارافينات المستقيمة المفصولة للكيروسين المعامل بدرجة (200م0) 


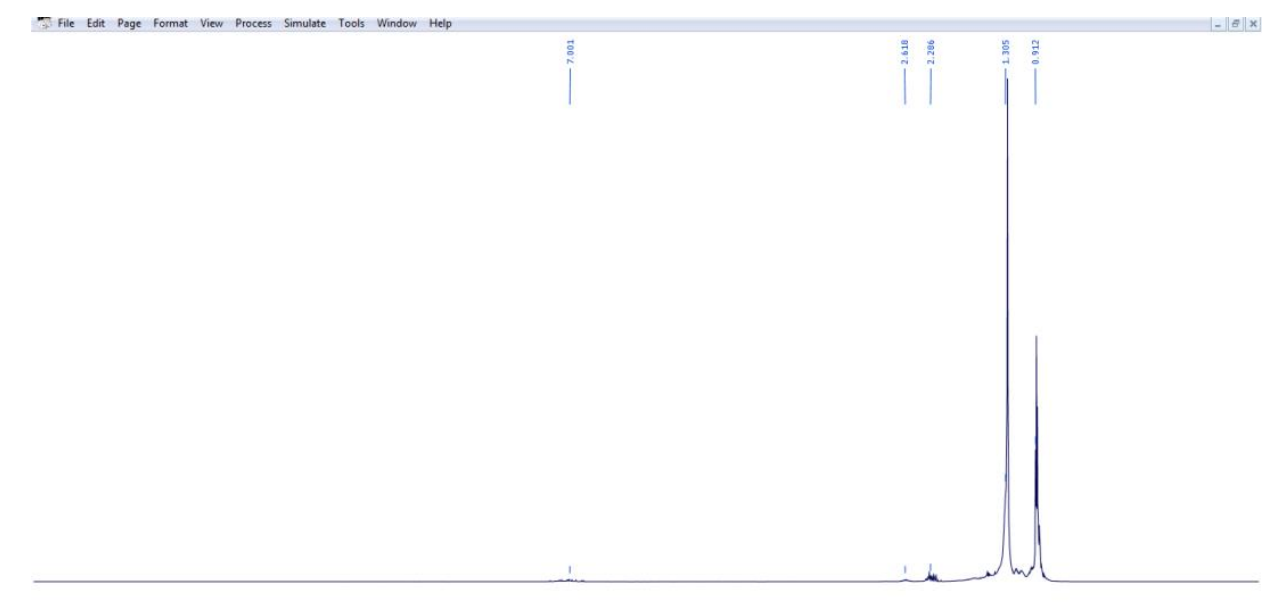

الثكل (12): طيف الرنين النووي المغناطيسي للبارفينات المستقيمة المفصولة للكيروسين المعامل بدرجة (250م0)

Conclusion

الاستنتاجات :

أظهرت الدراسة أن حفاز البلاديوم المحمول على الالومينا والمحصل عليه من خام البوكسايت يمتاز بما يأتي:

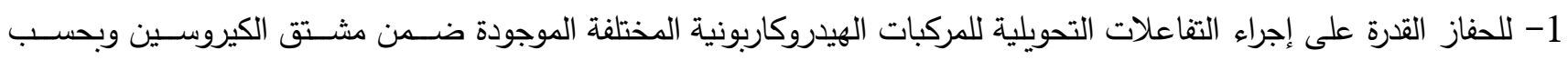
ظزوف المعاملة المختلفة .

2-أظهر الحفاز فاعلية إتجاه تفاعلات الحل الحفازي والازالة الهيدروجينية لتكوين المركبات الاوليفينية بدرجات (150-200 م²) ونسبة الحفاز 1\% وبزمن (1) ساعة.

3- أظهر الحفاز فاعلية كبيرة إتجاه الازالة الهيدروجينية والاصـلاح التركيبي بدرجة حرارة ( 250م²) ونسبة حفاز (2\%) وبزمن (2) ساعة. 4- لوحظ تراجع في قدرة الحفاز على إجراء التفاعلات التحويلية بزيادة نسبته إلى (3\%).

\section{Acknowledgement}

شكر وتقدير:

يتقدم الباحثان بالثكر والتقدير لقسم الكيمياء في كلية التربية للعلوم الصرفة - جامعة الموصل وإلى كلية الصيدلة جامعة الموصل-

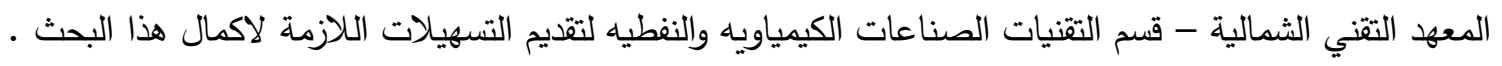

\section{References : المصادر}

1- Chatterjee, k. k, "Uses of Industrial Minerals, Rocks and Freshwater", Nova Science Publishers, Inc. New York, pp.53-61 . (2009).

2- Bradossy, G . and Aleva, G. J. I. 'lateritic Buaxites: Development in Economic ' Elsevier Sci . ' publ'pp. 642 . (1990)

3- Bolka ' T. " " Mineral of the month: Bauxite " Journal of the chip anlick Newslett ' vol. 54 ' No. 7 . (2008).

4- Bray 'E. L. " Bauxite and Alumina Staistics and Information" 'u. s. Geological Survey' pp. 1 3(2007).

5- Parkash, S., "Petroleum Fuels Manufacturing Handbook", McGraw-Hill Companies,Inc.,p.49. (2010).

6- Dhnwn, A. A., Ph.D.Thesis, University of Mosul. (2000). 
7- Salih, W.M., Master Thesis, University of Mosul. (2002).

8- Ghazal R.Y.," Thermal catalytic solution of Kirkuk oil kerosene by molecular sieves $\left(5 \mathrm{~A}^{0}\right)$ Vol18,PP.20-30.

9- Ebdallh, Ph.D.Thesis, University of Mosul(2011).

10- Al-Jburi M .I., Master Thesis, University of Mosul (2013).

11- Sussman, J., "Physical Method in Determinative Mineralogy", Clay Minerals "‘PP. 317- 326. (1977).

12- Aldabbagh S.M "Producing alum from local bauxite ores", Proceedings of the Continuing Education Course , University of Mosul (2008).

13- Review of Johnson Matthey pic , u.k.," The Catalyst Technical handbook" , pp. 5-9. (2008),

14- Talukdar A.K, Bhattacharyya K.G. and Sivasanker S, "Hydrogenation of phenol over platinum and palladium catalysts",Journal of Applied supported Catalysis, Elsevier Science Publishers, Vol.96 pp.229-239.,(1993).

15- Seshu, N. Babu,N.Lingaiah,Rajesh Gopinath,p.siva sankar Reddy, and p.s.ai Prasad Inorganic and physical chemistry Division,India 8,2006:In Final Form:February21,(2007).

16- Hoppe,A., , "Advances in petroleum chemistry and Refining ", Mc Ketta (ed.) ,vol .8 Interscience publishers, Inc .New york, pp. 657- 661. (1964)

17- Standard methods of the Institute of petroleum Ip 145/55,(1959), pp. 354-360.

18- Brow , M.E. , (2004) , "Introduction to Thermal Analysis" , 2nd . Ed." , Kluwer Academic Publisher, p.p. 19-28 . G7S 4K8 . 